\title{
Costs and benefits of Daphnia defense against Chaoborus in nature
}

\author{
Wiebke J. Boeing, Björn Wissel, and Charles W. Ramcharan
}

\begin{abstract}
To estimate costs and benefits of antipredator defenses in the Chaoborus-Daphnia system, we employed lake enclosures wherein controls $(\mathrm{C})$ had no predators, the predation $(\mathrm{P})$ treatment had freely swimming Chaoborus, and the kairomone $(\mathrm{K})$ treatment predators were sequestered in a mesh tube apart from the Daphnia. Population growth (r) of two Daphnia pulex clones, one responsive (RC) and the other nonresponsive (NRC) to Chaoborus kairomone, was estimated for each predator treatment. Cost of defense was calculated as $r_{(\mathrm{C}, \mathrm{RC})}-r_{(\mathrm{K}, \mathrm{RC})}$. Benefit was calculated as $r_{(\mathrm{P}, \mathrm{RC})}-r_{(\mathrm{P}, \mathrm{NRC})}$. Antipredator defenses of Daphnia towards Chaoborus kairomone led to a $32 \%$ reduction in population growth in nature. The benefit of the defense, however, was a short-term $68 \%$ enhanced population growth by a responsive over a nonresponsive clone in the presence of the actual predation threat. The benefit of the defense exceeded the cost, but cost was nevertheless substantial. Our results verify that the in situ effects of Chaoborus on Daphnia involve direct and indirect impacts.
\end{abstract}

Résumé : Afin d'évaluer les coûts et les bénéfices des défenses contre les prédateurs dans le système ChaoborusDaphnia, nous avons utilisé une série d'enclos lacustres: les enclos témoins (C) ne contenaient aucun prédateur, les enclos de prédation (P) avaient des Chaoborus en nage libre et les enclos de kairomone (K) contenaient des Chaoborus enfermés dans des tubes de grillage séparément des Daphnia. Nous avons mesuré la croissance de la population ( $r$ ) chez deux clones de Daphnia pulex, l'un (RC) sensible et l'autre insensible (NRC) à la kairomone de Chaoborus. Les coûts de la défense sont représentés par $r_{(\mathrm{C}, \mathrm{RC})}-r_{(\mathrm{K}, \mathrm{RC})}$ et les bénéfices par $r_{(\mathrm{P}, \mathrm{RC})}-r_{(\mathrm{P}, \mathrm{NRC})}$. Les défenses contre les prédateurs de Daphnia en réaction à la kairomne de Chaoborus entraînent une réduction de $32 \%$ de la croissance de la population en nature. Les bénéfices de la défense sont, par ailleurs, une croissance additionnelle à court terme de la population de l'ordre de $68 \%$ chez le clone sensible, par rapport au clone insensible, en présence d'une menace réelle de prédation. Les bénéfices de la défense dépassent les coûts, bien que ces derniers soient importants. Nos résultats confirment que les effets in situ de Chaoborus sur Daphnia impliquent des impacts directs et indirects.

[Traduit par la Rédaction]

\section{Introduction}

Our concept of the processes that shape food webs is typically focused on direct predator consumption of prey (e.g., Carpenter et al. 1985; McQueen et al. 1989; Ramcharan et al. 2001) and not on the indirect and ancillary costs of predation to prey populations. In some cases, this neglect is due to a lack of estimates of these ancillary costs in nature. A good example is the Chaoborus-Daphnia predator-prey system. Although this system is very well studied, plays an important role in lake food webs, and the antipredator defenses of the prey against the predator are well known, the costs and benefits of the defenses have not been estimated in nature, until now.

In the pelagic of lakes and ponds, Daphnia populations suffer heavy losses to predation by the invertebrate predator
Chaoborus (Kajak and Rybak 1979; Hanazato 1990; Liljendahl-Nurminen et al. 2003) and employ a variety of defenses against this predator. The defenses include changes in life history, the growth of protective spines, and the adoption of antipredator behavior. Life history changes involve a shift towards larger sized individuals at first reproduction and production of fewer but bigger offspring (Spitze 1992; Weber and Declerck 1997; Riessen 1999). This defense is effective, as Chaoborus are mouth-gape limited and preferably prey on smaller individuals (Pastorok 1981). Protective spines on the dorsal lower margin of the head (neck spines) of juvenile instars have been shown to increase escape rate from Chaoborus attacks by up to $60 \%$ (Krueger and Dodson 1981; Parejko 1991; Repka et al. 1995). The antipredator behavior seems designed to reduce spatial overlap between the prey and predator. Since Chaoborus usually remains deep,

Received 10 March 2004. Accepted 20 January 2005. Published on the NRC Research Press Web site at http://cjfas.nrc.ca on 9 June 2005.

J18024

W.J. Boeing ${ }^{\mathbf{1 , 2}}$ and B. Wissel. Department of Biological Sciences, Louisiana State University, Baton Rouge, LA 70803, USA.

C.W. Ramcharan. ${ }^{3}$ School of the Coast and Environment, Louisiana State University, Baton Rouge, LA 70803, USA.

${ }^{1}$ Corresponding author (e-mail: wboeing@nmsu.edu).

${ }^{2}$ Present address: Department of Fishery and Wildlife Sciences, New Mexico State University, Las Cruces, NM 88003-0003, USA.

${ }^{3}$ Present address: Department of Biology, Laurentian University, Sudbury, ON P3E 2C6, Canada. 
in darker water during the daytime (Tjossem 1990; Voss and Mumm 1999), Daphnia avoid this predator by migrating upwards (Dodson 1988; Ramcharan et al. 1992). The effectiveness of this defense in unknown because of the practical difficulties involved in studying larger scale pelagic processes in the laboratory.

In nature, there are vertical gradients of temperature, oxygen, light, UV radiation, and food quality and quantity that can all have important effects on the vertical position of Daphnia in the water column (Davidson et al. 1998; Lampert et al. 2003; Winder et al. 2003). In fact, only recently has it been demonstrated that the behavioral defense of Daphnia against Chaoborus is anything but a laboratory phenomenon and actually occurs under near-natural conditions (Nesbitt et al. 1996). Since the behavioral defense against Chaoborus is inducible, the defense should entail a cost (Dodson 1974; Havel 1987; Schwartz 1991). Costs have been estimated for the morphological and life history defenses of Daphnia spp. to Chaoborus, at least in laboratory studies or theoretical models (reviewed by Tollrian and Dodson 1999), and were found to range from no costs to a $58 \%$ decrease in fitness. However, like the benefit, the costs of the behavioral defense against Chaoborus have never been included in food web models because these costs are difficult to estimate in the laboratory. As a result, although the Chaoborus-Daphnia system is an important trophic link in pelagic food webs and is also one of the best-known examples of inducible defenses, neither the benefits nor the costs of the combined defenses have ever been estimated.

Here, we estimate the costs incurred when Daphnia adopts behavioral and morphological defenses against Chaoborus and also the benefits of those defenses, all in terms of the intrinsic rate of population growth, $r$. Two aspects of the response of Daphnia to Chaoborus kairomone make our approach possible. Since the strength of antipredator behavior varies among clones, the benefit of the defense can be estimated as the difference in $r$ between a protected and an unprotected clone when exposed to the predator. And since the defense is inducible for the protected clone, the cost of the defense can be estimated as the difference in $r$ between population growth in controls and those exposed to just Chaoborus kairomone.

We conducted an enclosure experiment to estimate the effects of the various defense mechanisms in terms of costs and benefits in nature. We used two Daphnia pulex clones, one that could employ antipredator defenses against Chaoborus (responsive clone) and one that could not (nonresponsive clone). Three different treatments were conducted for each clone: predation (Daphnia together with the Chaoborus predators), kairomone (Daphnia were only exposed to predator kairomone), and control (Daphnia grew without any influence of predators). The difference in population growth between the control and kairomone treatment for the responsive clone should represent only the cost of the antipredator defenses, independent of the cost of predation (Table 1). When comparing population growth rates of the two clones in the predation treatments (normalized for the respective controls to account for clonal differences in life history parameters), the responsive clone is expected to have
Table 1. Predicted growth rates of Daphnia clones according to different treatments and calculation of costs and benefits.

\begin{tabular}{llll}
\hline & Control & Kairomone & Predation \\
\hline Responsive & $A$ & $C$ & $B$ \\
Nonresponsive & $D$ & $F$ & $E$ \\
\hline
\end{tabular}

Note: The responsive clone exhibits antipredator behavior. The nonresponsive clone does not exhibit antipredator behavior. $A, D$, and $F$, maximum population growth rate under given environmental conditions; $C$, growth rate affected by antipredator behavior; $B$, growth rate affected by both antipredator behavior and some predation; $E$, minimum growth rate, full predation pressure, no costs of defense. Costs of predation $=E-$ $D$, costs of antipredator behavior $=A-C$, and benefits of antipredator behavior $=(B-E)-(A-D)$. To calculate costs and benefits as a percentage, both $A$ and $D=100 \%$.

higher growth rates, which would be the benefit of the defenses (Table 1).

\section{Materials and methods}

In a previous laboratory experiment, we evaluated 37 D. pulex clones, which were established as laboratory cultures by isolating individual females from 13 different water bodies, for their migration behavior, neck spine production, and life history responses (population growth rate $r$, neonate size, and size at first reproduction) in response to Chaoborus kairomone. Clones were determined to be genetically distinct by microsatellite analysis (Boeing 2002). Both clones used for the field experiment were collected in New York State, USA. One clone originated from a pond with a high density of Chaoborus predators but no fish, while the other clone came from Honeoye Fingerlake in which planktivorous fish are the main predators for Daphnia. The pond clone reacted strongly to Chaoborus kairomone by migrating upward in the water column, producing neck spines, and showing an increased population growth rate caused by earlier age at maturity as well as larger clutch sizes. This clone will hereafter be referred to as the responsive clone. The other clone did not show any response to Chaoborus and was designated the nonresponsive clone (Table 2). Among all the clones examined, the one isolated from Honeoye Fingerlake was one out of only three clones that did not respond to Chaoborus kairomone in the laboratory. We could not find two clones that differed fundamentally in their response to Chaoborus kairomone within one lake. The two clones were chosen based on their similarity in $r$, resistance to handling stress, and extremes of response and nonresponse to Chaoborus kairomone (Table 2) (Boeing 2002). Under ideal circumstances, multiple clones of each type would have been preferred. Unfortunately, we did not have the resources to run such an experiment in the field. Using multiple clones in the same enclosure bag would have created confounding competitive effects. Therefore, using only one clone for each type was the necessary trade-off to test our hypotheses. Both clones were grown to high densities in the laboratory before the beginning of the experiment.

\section{Enclosure experiments}

We estimated the costs and benefits of antipredator defenses toward Chaoborus under near-natural conditions with an enclosure study conducted during the summer of 1999 . 
Table 2. Origin (pond or lake) and behavioral, morpholgical, and life history defenses of the responsive and nonresponsive Daphnia clones in laboratory evaluations.

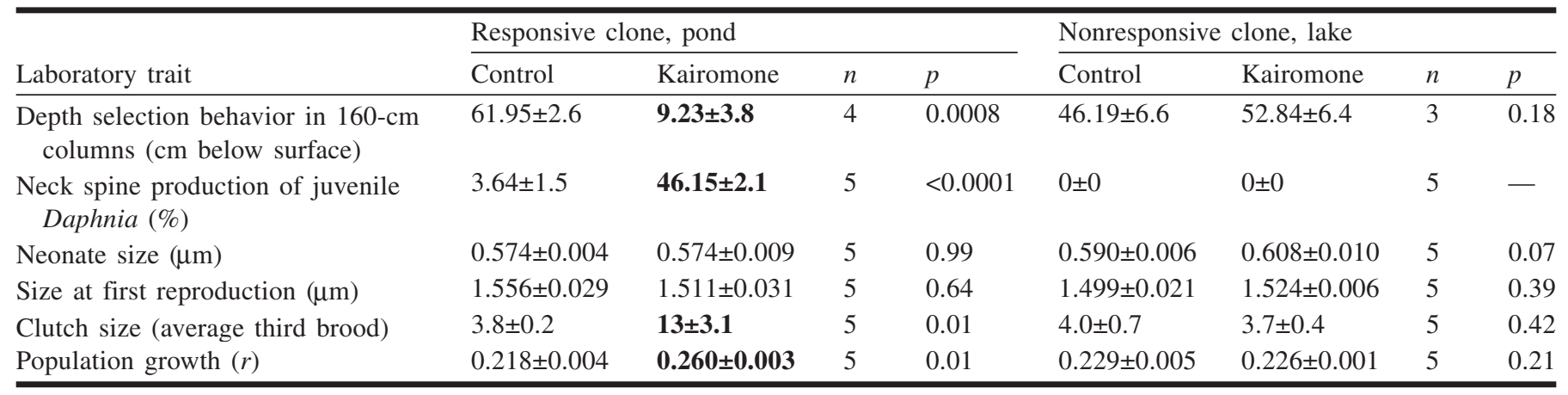

Note: Traits are listed as means \pm 1 SE. Bold numbers indicate a significant difference from the control ( $p<0.05)$, and $p$ values were obtained with two-tailed Student's $t$ tests. $n$ is the sample size.

The treatments were the two Daphnia clones (responsive and nonresponsive) and three predator regimes (control, predation, and kairomone) in a factorial design with four replicates (24 enclosures in total). Enclosures consisted of transparent, non-UV-coated polyethylene, had a diameter of $1 \mathrm{~m}$, and enclosed $7.5 \mathrm{~m}$ of the water column $(5800 \mathrm{~L})$. Each enclosure was suspended from a wooden frame, sealed at the bottom, and tied with a rope to a stabilizing anchor.

The enclosures were placed in Costello Lake $\left(78^{\circ} 19^{\prime} \mathrm{W}\right.$, $45^{\circ} 36^{\prime} \mathrm{N}$, Algonquin Park, Ontario, Canada). Costello Lake is a medium-sized (33.5 ha), oligotrophic (total phosphorus = $11.1 \mu \mathrm{g} \cdot \mathrm{L}^{-1}$ ), moderately brown-stained lake (dissolved organic carbon varies around $4 \mathrm{mg} \cdot \mathrm{L}^{-1}$, Secchi depth about $3 \mathrm{~m}$ ) of circumneutral $\mathrm{pH}$. High densities of Chaoborus trivittatus and Chaoborus flavicans as well as planktivorous fish are present throughout the summer (W.J. Boeing, personal observation). The zooplankton community is dominated by copepods but includes large cladocerans such as Holopedium gibberum, Daphnia dubia, D. pulex, Daphnia dentifera, and Daphnia longiremis (B. Wissel, unpublished data). Costello Lake represents an average lake for the region that was also secluded and human disturbance was minimal.

The enclosures were filled with lake water drawn from the upper metalimnion ( $2.5 \mathrm{~m}$ depth) to obtain intermediate nutrient, algae, and zooplankton values. The water was filtered through a $202-\mu \mathrm{m}$ mesh, thereby removing large zooplankton such as Daphnia and Chaoborus while allowing the smaller natural zooplankton community to pass through. Afterwards, all enclosures were covered with screening (2-mm mesh) to prevent Chaoborus oviposition. Two days after filling, approximately 500 individuals from one or the other Daphnia clones were added to each of 24 randomly chosen enclosures. We conducted vertical hauls with a plankton net (30 $\mathrm{cm}$ in diameter, $130-\mu \mathrm{m}$ mesh size) once a week to check Daphnia densities and on 3 July, after 14 days of growth, densities were adjusted to 1 individual $\cdot \mathrm{L}^{-1}$ by removing extra Daphnia using plankton nets. A second, smaller tube $(30 \mathrm{~cm}$ in diameter, $7 \mathrm{~m}$ long, and 495-L volume) made of $250-\mu \mathrm{m}$-mesh screening was then suspended in the middle of each enclosure. The mesh tube was used to sequester Chaoborus from Daphnia in the kairomone treatments while allowing free exchange of water, algae, and predator chemicals. On 4 July (day 1 of our experiment), C. trivittatus was added at a density of 1.1 individuals $\cdot \mathrm{L}^{-1}$ to the randomly assigned predation treatments and the same total number of predators were placed in each of the mesh bags of the kairomone treatments. Chaoborus were caught the previous night from nearby Walker Lake with a 2-mmmesh net. Costello Lake had high densities of Holopedium at that time that we could not keep out of the net and would have added undesired organic material to our enclosures. Chaoborus inside the mesh bags were fed with Daphnia that were removed from enclosures the previous day. No Chaoborus were put into the control. We chose $C$. trivittatus because it is the species in North America that remains in the planktonic stage throughout most the summer and is also a large species able to feed on even large Daphnia (e.g., Pastorok 1981). On 16 July (day 13) and again on 26 July (day 23), Chaoborus were added to densities of 1.2 individuals $\cdot \mathrm{L}^{-1}$ and 0.9 individual $\cdot \mathrm{L}^{-1}$, respectively. This assured that, despite removal by sampling, predator density stayed above 0.7 individual $\cdot \mathrm{L}^{-1}$, a moderate natural density for Chaoborus.

We added moderate amounts of nutrients $\left(10 \mu \mathrm{g} \mathrm{P} \cdot \mathrm{L}^{-1}\right.$ as $\mathrm{P}_{2} \mathrm{O}_{5}, 11 \mu \mathrm{g} \mathrm{N} \cdot \mathrm{L}^{-1}$ as $\mathrm{NH}_{4}$ and $\left(\mathrm{NH}_{2}\right)_{2} \mathrm{CO}, 9 \mu \mathrm{g} \mathrm{K} \cdot \mathrm{L}^{-1}$ as $\mathrm{K}_{2} \mathrm{O}, 0.015 \mu \mathrm{g} \mathrm{B} \cdot \mathrm{L}^{-1}, 0.05 \mu \mathrm{g} \mathrm{Cu} \cdot \mathrm{L}^{-1}, 0.11 \mu \mathrm{g} \mathrm{Fe} \cdot \mathrm{L}^{-1}$, $0.04 \mu \mathrm{g} \mathrm{Mn} \cdot \mathrm{L}^{-1}, 3.6 \times 10^{-4} \mu \mathrm{g} \mathrm{Mo} \cdot \mathrm{L}^{-1}$, and $0.04 \mu \mathrm{g} \mathrm{Zn} \cdot \mathrm{L}^{-1}$ ) to each enclosure. The purpose was to maintain pelagic algae productivity by replacing lost nutrients due to algae sedimentation and eliminate food limitation as a confounding factor in Daphnia population growth.

\section{Sampling}

We sampled at 4-day intervals between 5 July (day 2) and 10 August (day 38). Zooplankton were collected with a closing net $(30 \mathrm{~cm}$ in diameter, $130-\mu \mathrm{m}$ mesh size) from four discrete depth intervals $(0-1,1-3$, and $3-5 \mathrm{~m}$ and $5 \mathrm{~m}$ to the bottom) and were preserved in $4 \%$ sugar-saturated formaldehyde (Haney and Hall 1973). Temperature and oxygen profiles were taken at $1-\mathrm{m}$ intervals with a probe (model 50B; YSI Incorporated, Yellow Springs, Ohio) lowered in the enclosures 1 day before collection of zooplankton samples.

We determined day-night distribution of zooplankton on days 10, 22, and 34. Daytime samples were typically taken around noon, while night sampling began $3 \mathrm{~h}$ after sunset, 
around midnight. Chlorophyll $a$ was determined from $0.5-\mathrm{L}$ samples pumped from $0-1,1-3$, and $3-7 \mathrm{~m}$ on days 6,18 , and 30 for three randomly selected enclosures per treatment. We could not sample all of the enclosures because of the time needed for processing. Water samples for chlorophyll $a$ were kept in the dark and processed immediately upon return to the laboratory. We separated the algae into edible $(<30 \mu \mathrm{m})$ and inedible $(>30 \mu \mathrm{m})$ fractions with a Nitex mesh and filtered both fractions onto a $\mathrm{GF} / \mathrm{C}$ filter $(1.2-\mu \mathrm{m}$ pore size). Filters were frozen at $-20{ }^{\circ} \mathrm{C}$ for up to 3 months. Filters were then sonicated and chlorophyll $a$ extracted in $100 \%$ acetone at $7{ }^{\circ} \mathrm{C}$ overnight. Chlorophyll $a$ concentration was measured with a fluorometer (model 10-005R; Turner Designs Inc., Sunnyvale, California).

\section{Sample enumeration and data analysis}

Enumeration took place under a dissecting microscope (model MZ8, Leica Microsystems Inc., Bannockburn, Illinois) that allowed magnification up to 50-fold. Daphnia and Chaoborus were counted for each sampling date. To estimate population densities, we counted at least 100 Daphnia for each depth $(0-1,1-3$, and $3-5 \mathrm{~m}$ and $5 \mathrm{~m}$ to the bottom) from each enclosure. If animal density was high, $10-\mathrm{mL}$ subsamples were enumerated. Daphnia were distinguished by eye between adults (approximately $>1.2 \mathrm{~mm}$ ) and juveniles (approximately $<1.2 \mathrm{~mm}$ ). Chaoborus were counted as either first and second instar $(<1 \mathrm{~cm})$ or third and fourth instar $(>1 \mathrm{~cm})$.

Neck spine size of Daphnia was scored according to Tollrian (1993), where a morphologically normal neck was $0 \%$, a little bump on the neck was $30 \%$, and a bump with convex sides was 50\% induction. Each separate spine accounted for an additional $10 \%$.

Population growth $(r)$ was estimated using the equation

$$
r=\left[\ln \left(N_{2}\right)-\ln \left(N_{1}\right)\right] / \Delta t
$$

where $N_{2}$ is the population density at time $t_{2}$ (later sampling date), $N_{1}$ is the population density at time $t_{1}$ (earlier sampling date), and $\Delta t$ is the difference between time $t_{1}$ and time $t_{2}$ in days.

For easier comparison, population growth rates are expressed as a percentage. To adjust for life history differences between the clones, we normalized population growth values for the controls. Control treatments of both clones were set to $100 \%$ and the kairomone and predation treatments were determined relative to the control of the same clone.

\section{Statistical analysis}

On 6 July (day 3), 2 days after adding the Chaoborus, a storm destroyed some enclosures: two controls and one predation treatment for the responsive clone and one control for the nonresponsive clone. An unbalanced analytical design was the result of the loss of some replicates.

Statistical evaluation was conducted using SAS software (version 8; SAS Institute Inc., Cary, North Carolina). We used repeated-measures analysis of variance (ANOVA) with depth as the repeated variable to compare temperature and oxygen profiles among treatments. Variation in chlorophyll $a$ among treatments was assessed with a three-way ANOVA using clones, predator treatment, and depth as independent variables. The effects of clone and predation regime on population growth rates, mean vertical distribution, and neck spine development were determined in separate analyses with two-way model III ANOVA (clones and predator treatments were fixed effects). The $p$ values were adjusted with Tukey's test, normality was tested using Shapiro-Wilk's test, and homogeneity of variances was assured by Bartlett's test.

\section{Results}

Temperature and oxygen were consistent among treatments and the lake (repeated-measures ANOVA, $p>0.05$ ). The epilimnion in both the lake and the enclosures was $3 \mathrm{~m}$ thick and temperature ranged between 20 and $25{ }^{\circ} \mathrm{C}$. The temperature dropped quickly below $3 \mathrm{~m}$ and reached values around $7{ }^{\circ} \mathrm{C}$ at the bottom of the enclosures. Oxygen levels stayed between 6 and $8 \mathrm{mg} \cdot \mathrm{L}^{-1}$. The edible fraction of chlorophyll $a(<30 \mu \mathrm{m})$ on day 6 was lower in the enclosures with the nonresponsive clone $\left(20 \mu \mathrm{g} \cdot \mathrm{L}^{-1}\right)$ than in those with the responsive clone $\left(35 \mu \mathrm{g} \cdot \mathrm{L}^{-1}\right)(p=0.001)$.

Neck spine induction differed between the two clones in the field as it did in the laboratory. The responsive clone produced neck spines only in the kairomone $(36.62 \% \pm$ $1.43 \%$ induction) and predation $(37.95 \% \pm 4.28 \%)$ treatments, while the nonresponsive clone failed to do so in all treatments (two-way ANOVA, $p<0.0001$ ).

Although in the laboratory, the population growth rate of the responsive clone in the kairomone treatment was higher than in the control owing to earlier maturation and larger brood sizes (Table 2), we could not confirm any differences in life history parameters in the field. We measured more than 120 Daphnia from each enclosure on day 10. There was no indication for increased body length of Daphnia owing to Chaoborus kairomone or predation treatment for either clone. We also did not find any evidence for a change in number of eggs per ovigerous female among treatments.

Vertical distribution during daytime was stable for all treatments in both clones for the first 14 days. Afterwards, the mean distribution dropped in all enclosures. Since the only night sample we have during that interval was on day 10, those are the data shown in the graph (Fig. 1). Predation regime had different effects on the vertical distribution of the two clones. Both clones preferred the epilimnion $(0-3 \mathrm{~m})$ during daytime (Fig. 1). However, only the responsive clone significantly decreased its mean vertical distribution by $1.11 \mathrm{~m}$ in response to predator kairomone (dashed lines in Fig. 1) (two-way ANOVA, $p=0.0077$ ). In the predation treatment, the responsive clone was $1.17 \mathrm{~m}$ higher when compared with the control $(p=0.0002)$. Chaoborus mainly remained in the deepest sample layer $(5-7 \mathrm{~m})$ in all predation treatment enclosures. At night, both clones showed patterns of reverse migration and moved to deeper water layers. The responsive clone distributed itself evenly throughout the water column in the control. The Daphnia in the kairomone treatment remained on average $0.75 \mathrm{~m}$ and in the predation treatment $1.53 \mathrm{~m}$ higher than in the control. The nonresponsive clone stayed more clustered at intermediate depths. The distributions of control and kairomone treatments were almost identical, while in the predation treatment, nonresponsive Daphnia were virtually absent in the 
Fig. 1. Boxplots of vertical depth distribution of Daphnia and Chaoborus on day 10 during the day and night in the controls (C), kairomone treatments $(\mathrm{K})$, and predation treatments $(\mathrm{P})$ for the $(a$ and $b)$ responsive clone and $(c$ and $d$ ) nonresponsive clone. The solid horizontal line is the median and the broken line is the mean. The box includes the second and third quartiles, and the deviation bars represent the 10th and 90th percentiles and the dots the 5th and 95th percentiles. Figures $1 a$ and $1 c$ are the day samples, and Figs. $1 b$ and $1 d$ are the night samples.
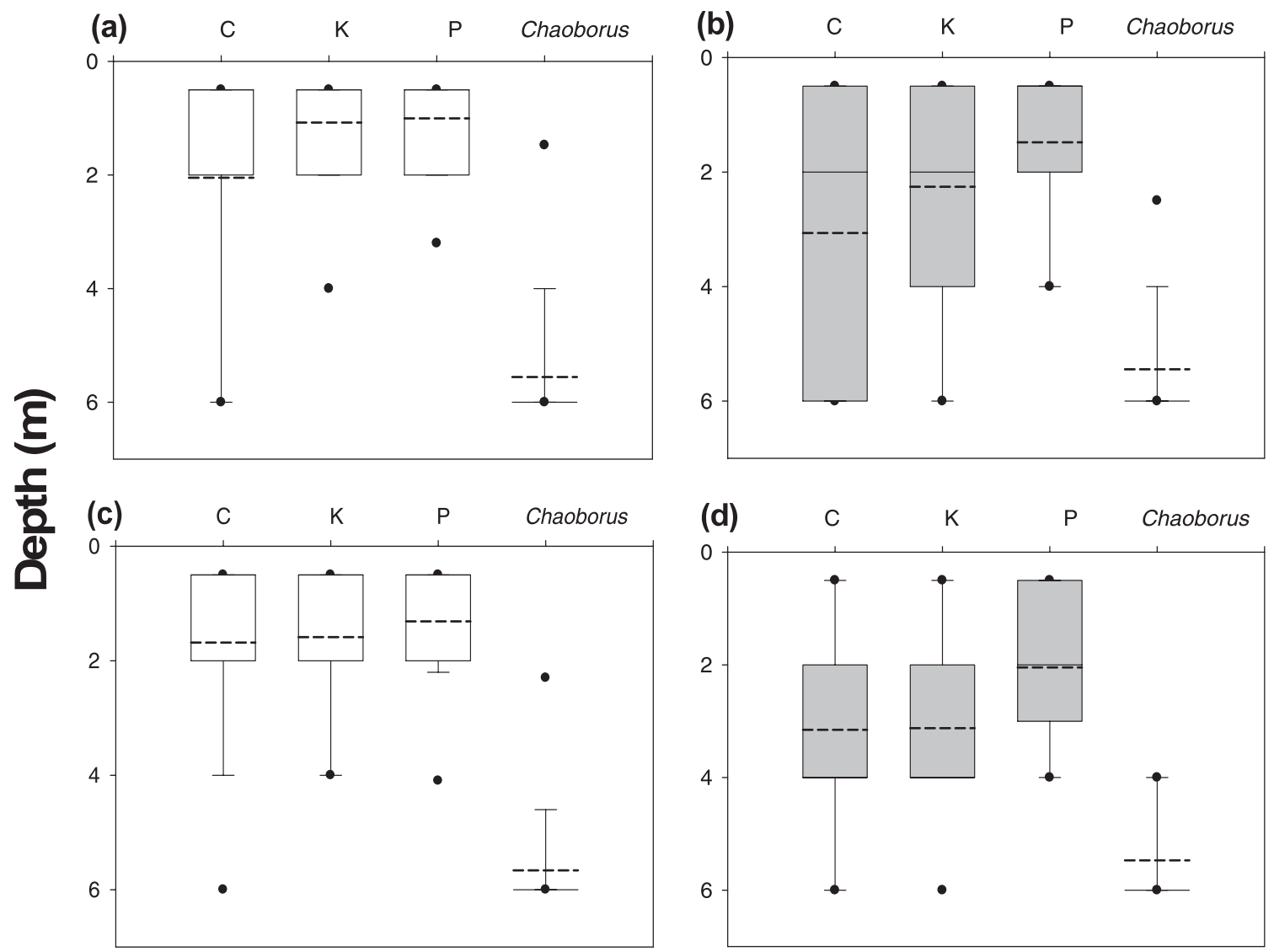

bottom of the enclosure bags, which led to a $1 \mathrm{~m}$ shallower distribution. Chaoborus showed no vertical migration pattern and remained at the bottom of the enclosures even at night.

On day 14, all treatments were at or past their peak of Daphnia population density. Therefore, we only present data for that time period, as this is relevant for the calculation of costs and benefits of Daphnia antipredator defense and density-dependent factors probably drive the declines of the populations. Population trajectories reveal that both clones had positive growth rates from day 0 to day 10 in the controls, after which the populations started to decrease (Fig. 2). For the responsive clone, population growth in the kairomone enclosures slowed for 9 days after addition of predators into the mesh bags. This caused a delay in the population peak of about 4 days. Similar to kairomone treatments, growth of the Daphnia population exposed to predation also slowed for 9 days after predator addition and peaked on day 14. The nonresponsive clone maintained higher overall densities than the responsive clone. Control and kairomone treatment of the nonresponsive clone did not differ from each other, and dynamics were comparable with the controls of the responsive clone. In the predation treatment, the nonresponsive clone showed a strong decrease shortly after predator addition and then grew to a maximum on day 14, 4 days after the control and kairomone enclosures had reached their maxima.

The time period of positive population growth (day 0 to day 10) of the control was used to calculate population growth rate for Daphnia in both the control and kairomone enclosures, and the differences in growth rates between different treatments were used to estimate the costs and benefits of defense between successive sampling dates (see Materials and methods) (Table 3). Both costs and benefits varied quite alot. Costs ranged from a low of $-48.4 \%$, indicating that Daphnia populations actually grew faster with predator kairomone, to a high of $153.3 \%$, indicating a strong cost of prey defense. The value for cost of the defense calculated over the entire period from day 0 to day 10 was $32.3 \%$. Although we did not observe a change in numbers of eggs per ovigerous female, by day 10 , the percentage of adult females that were ovigerous was significantly lower in the kairomone and predation treatments of the responsive clone than in the control (two-way ANOVA, $p=0.034$ ). Similarly, the benefit of the defense varied from a low of $-146.8 \%$, indicating that predation somehow benefited Daphnia, to a high value of $68.4 \%$, indicating a strong advantage of the defense. This latter value was estimated from day 2 to day 6 , the only period when Daphnia suffered clear losses to Chaoborus predation; thus, we believe that the value of 
Fig. 2. Population dynamics (mean \pm SE) of Daphnia clones between days 0 and 14. The arrows indicates Chaoborus addition on day 1. (a) Responsive clone; (b) nonresponsive clone. Shaded symbols, control; open symbols, kairomone; solid symbols, predation.

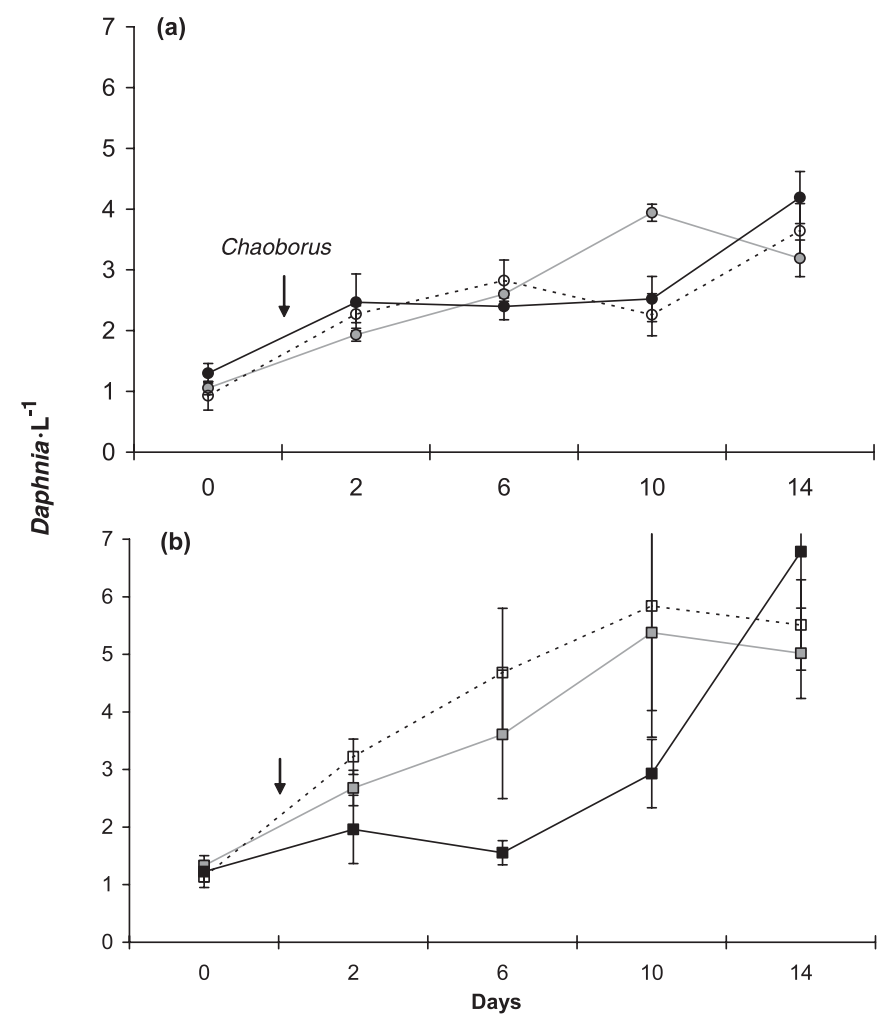

$68.4 \%$ is the best estimate of the benefit of antipredator defenses.

\section{Discussion}

To summarize the results, the environmental conditions within the enclosures closely matched each other and the lake and were also well within the ranges of tolerance for both Daphnia and Chaoborus. Oxygen concentration was always above $6 \mathrm{mg} \cdot \mathrm{L}^{-1}$, which would not have been stressful for any of the species in our experiments (Davidson et al. 1998; Sell 1998). Besides Daphnia, there were also up to 20 Bosmina $\cdot \mathrm{L}^{-1}$ and 2 copepods $\cdot \mathrm{L}^{-1}$, which could have served Chaoborus as prey. Levels of chlorophyll $a$ were a little higher in the treatments with the nonresponsive than in those with the responsive clone.

In terms of antipredator responses, the field results matched our expectations based on the laboratory bioassay (Boeing 2002) fairly well. Neck spines were produced in the kairomone and predation treatments but only by the juveniles of the responsive clone. However, in response to either Chaoborus kairomone or real predation, there was no evidence in the clones of a life history response (increase or decrease in egg production or changes in body size). Estimates of population growth rate showed slightly higher values of $r$ for the nonresponsive clone compared with the responsive clone. The two clones exhibited some differences in vertical distribution in the control enclosures. The nonresponsive clone had a tendency to stay up higher in the water column during the day and was not as evenly distributed as the responsive clone at night. The one unexpected result was that not just the responsive clone but also the nonresponsive one exhibited a reverse diurnal migration pattern, migrating down at night. However, as seen in the laboratory bioassays, only the responsive clone reacted to the kairomone treatment with a higher vertical position. In contrast, the nonresponsive clone had the same behavior in the kairomone treatment as in the controls. Including Nesbitt et al. (1996), this is now only the second time that the behavioral response to Chaoborus has been induced in nature. For the responsive clone, maintaining a high vertical position in the kairomone treatments relative to the controls during both day and night was a good defensive strategy, as Chaoborus remained at depth. In the predation enclosures, both clones remained highest in the water column among all of their treatments but, as with the kairomone treatments, the responsive clone again showed the stronger avoidance response (change in position relative to the controls). The absolute vertical position of the nonresponsive clone in the predation treatment was shallower than that of the control or kairomone treatment, which might have been due to predation losses to Chaoborus in deeper water layers rather than a behavioral response.

We found that defending against Chaoborus caused a reduction of $32.3 \%$ in Daphnia population growth, and we estimated the benefits to be $68.4 \%$ enhanced population growth, exceeding the costs by $36 \%$. This was the first time that benefits for Daphnia antipredator defense were estimated and it was also the first time that costs were measured in nature and included the behavioral migration response. The reduction in population growth was probably due to the decreased percentage of ovigerous females in the kairomone treatments.

The calculation of the cost of antipredator defense was fairly straightforward, as the differences in population growth between control and kairomone enclosures were compared within the same clone (responsive). We estimated the cost of antipredator defenses to be a $32 \%$ reduction in population growth in the kairomone compared with the control treatments. The populations in the controls had a higher population growth rate and reached maximum population densities faster than those exposed to kairomone. The reduction of population growth in the kairomone treatment can only be explained by induced antipredator defenses.

Several different mechanisms could have accounted for the cost of the antipredator defense. We observed both neck spine production and upward migration in the responsive clone. The neck spine production itself probably did not contribute to lower population growth. This clone did not experience a reduced fertility rate owing to Chaoborus kairomone exposure in previous laboratory experiments in which neck spine production exceeded the induction observed in the field (Boeing 2002). However, the behavioral upward migration probably did cause the observed cost. According to traditional belief (Bottrell 1975; Stich and Lampert 1984), Daphnia in the kairomone treatments experienced warmer temperatures than in the control treatments, which should enhance population growth in the kairomone treatment by $10 \%$ compared with the control treatments 
Table 3. Population growth rates $(r)$ of responsive and nonresponsive Daphnia clones for different time intervals and calculation of costs and benefits for different time intervals.

\begin{tabular}{|c|c|c|c|c|c|c|c|c|}
\hline \multirow[b]{2}{*}{ Days } & \multicolumn{3}{|c|}{ Responsive clone $r$} & \multicolumn{3}{|c|}{ Nonresponsive clone $r$} & \multirow[b]{2}{*}{$\begin{array}{l}\text { Costs } \\
(\%)\end{array}$} & \multirow[b]{2}{*}{$\begin{array}{l}\text { Benefits } \\
(\%)\end{array}$} \\
\hline & $\begin{array}{l}\text { Control } \\
(n=2)\end{array}$ & $\begin{array}{l}\text { Kairomone } \\
(n=4)\end{array}$ & $\begin{array}{l}\text { Predation } \\
(n=3)\end{array}$ & $\begin{array}{l}\text { Control } \\
(n=3)\end{array}$ & $\begin{array}{l}\text { Kairomone } \\
(n=4)\end{array}$ & $\begin{array}{l}\text { Predation } \\
(n=4)\end{array}$ & & \\
\hline $2-6$ & $0.07 \pm 0.00$ & $0.05 \pm 0.00$ & $-0.01 \pm 0.00$ & $0.07 \pm 0.01$ & $0.09 \pm 0.01$ & $-0.06 \pm 0.01$ & 26.58 & 68.41 \\
\hline $6-10$ & $0.10 \pm 0.00$ & $-0.06 \pm 0.01$ & $0.01 \pm 0.00$ & $0.1 \pm 0.01$ & $0.06 \pm 0.01$ & $0.16 \pm 0.01$ & 153.27 & -146.77 \\
\hline $0-10$ & $0.13 \pm 0.01$ & $0.09 \pm 0.01$ & $0.07 \pm 0.01$ & $0.14 \pm 0.02$ & $0.16 \pm 0.01$ & $0.09 \pm 0.01$ & 32.25 & -11.78 \\
\hline
\end{tabular}

Note: Values represent mean $\pm \mathrm{SE}$, and $n$ is the sample size.

(considering that the average metalimnion temperature was $10{ }^{\circ} \mathrm{C}$ below the epilimnion temperature and $20 \%$ more Daphnia stayed below the thermocline in the controls than in the kairomone treatment). However, recent research is suggesting that temperature can have negative effects on large body sized Daphnia as energy becomes limiting (decreased assimilation - metabolism relationship) (Weetman and Atkinson 2004). Another likely cost is increased competition for food owing to crowding. As daphnids migrate upwards, they use a smaller volume of the water column and would compete more strongly for the available food. Steiner (2003) demonstrated that effects of competition can outweigh actual Chaoborus predation. Moreover, feeding rate may itself be reduced in the presence of Chaoborus kairomone (Ramcharan et al. 1992) or crowding chemical (Lurling et al. 2003), which may further reduce somatic growth rates. Although the number of eggs produced per ovigerous female was the same among treatments for the responsive clone, there was a significant decrease in the percentage of females producing eggs, which might be explained by competition or crowding. Ebert (1993) found a reduction in the number of eggs owing to food limitation in Daphnia magna, while Lynch (1989) and Boersma (1995) also observed reduction in egg size of $D$. pulex and Daphnia galeata, respectively. We did not measure egg size and could find no reference to reduction in the percentage of ovigerous females owing to resource limitation. Exposure to UV radiation might have also contributed to the cost of antipredator defense (Williamson 1996). Harmful radiation can penetrate down to about $1 \mathrm{~m}$ in lakes with a dissolved organic carbon content comparable with that of Costello Lake (Leech and Williamson 2000). Migrating upwards in the daytime as a response to Chaoborus kairomone may have negatively affected Daphnia survival and reproduction (Grad et al. 2001).

Our estimate of $32.3 \%$ reduction in $r$ is a higher value for Daphnia's defense against Chaoborus than has been estimated in the laboratory. Exposure to Chaoborus kairomone in the laboratory has had negative effects on Daphnia population growth that varied widely between $0 \%$ and $28 \%$ (Havel 1987; Riessen and Sprules 1990; Walls et al. 1991). The variation can be partly explained by differences among experiments in exposure time to predator kairomone (Riessen 1999) as well as genetic variance. However, all of these laboratory estimates could consider only morphological and life history costs. Only in nature could the cost of behavioral defenses be properly estimated, and in our study, it is likely that enhanced competition for food and exposure to UV radiation reduced Daphnia $r$ more than the cost of the morphological and life history defenses.

We calculated the benefits of antipredator defense as the difference in predation impact (difference in $r$ ) between the responsive and nonresponsive clones. This approach is efficient but can be confounded by differences in $r$ between the clones in the controls. In the laboratory bioassays, the two clones had similar $r$ values. However, in the field, the nonresponsive clone had a higher $r$ and reached a higher maximum density than the responsive clone. Also, slight differences in vertical distribution in the control treatments between the clones could potentially interfere with the results. As the estimate for the benefit was adjusted for differences in $r$ of the controls, the effects of different population growth rates were minimized. The higher density of the nonresponsive clone was likely the reason why levels of chlorophyll $a$ were reduced in the enclosures with this clone.

The behavior of the predator also affected our estimates of the benefits of the defense. Chaoborus failed to show a strong upward migration at night that is typically found in nature (Tjossem 1990; McQueen et al. 1999). This might be due to a shock response. Dawidowicz (1993) observed in his experiment that after introduction into 1-m experimental tubes, Chaoborus initially failed to migrate, and only after about 3 weeks did approximately $50 \%$ of the population rise to the epilimnion at night. Similarly, Chaoborus in other enclosure experiments showed only a very subtle upward migration during nighttime (Nesbitt et al. 1996; Young 2002; B. Wissel, unpublished data). Without upward migration, overlap between predator and prey would have been low, thereby reducing predation impact. Calculations of an overlap index (Williamson and Stoeckel 1990) between the responsive and nonresponsive clones in our experiment revealed negatively correlated prey and predator distributions in both clones during day and night. Certainly, a predator has to encounter its prey for predation to occur. In our experiments, we know only that on day 10 , there was little overlap between Chaoborus and Daphnia, yet on previous days, there was a clear predation effect. It is possible that early in the experiment, the predator had a day-night vertical distribution that caused higher overlap with the prey. It is also possible that Chaoborus stayed in the lower water layers from the start to the end of the experiment but that this degree of overlap was sufficient to reduce prey numbers when prey populations were low. As the prey increased, Chaoborus could not show a numerical response, and the proportion of prey lost to predation would fall. The reduction in population growth rate between days 2 and 6 for both 
clones as well as the shallower distribution in the predation treatments can only be explained by actual predation on Daphnia by Chaoborus, which allowed us to estimate a benefit to Daphnia's defense.

Our estimate of a $68 \%$ reduced mortality rate owing to antipredator defenses is higher than laboratory estimates for the benefits of other defenses. Neck spines alone increase escape rate from Chaoborus attacks by up to $60 \%$ (Krueger and Dodson 1981; Parejko 1991; Lüning 1995). The high estimate in our study might be due to a simultaneous benefit of behavioral and morphological defenses.

In summary, ours is the first attempt to measure the costs and benefits of Daphnia's antipredator defenses against Chaoborus in nature. In this first approximation, we found a reduction in population growth of $32 \%$ owing to antipredator defenses, probably as a result of decreased energy efficiency of Daphnia owing to higher temperature exposure, detrimental effects of UV radiation, crowding, and competition for limited food resources in the upper water layer. The estimated benefits of the antipredator defenses of $68 \%$ outweigh the costs, as would be expected (Sih 1982; Dill and Fraser 1984; Kohler and McPeek 1989). Over the course of a growing season, with benefits exceeding costs by $36 \%$, the advantage of an invulnerable over a vulnerable clone can be considerable, even if Chaoborus predation is limited to short periods of time. Although Daphnia are an ideal study organism to measure costs and benefits of inducible defenses, clonal variety is large and different combinations of behavioral, morphological, and life history defenses occur. Therefore, costs and benefits of Daphnia antipredator defense to Chaoborus will vary depending on clonal strength of the various defenses as well as the habitat. Nevertheless, this is the first time that the costs and benefits associated with these defenses were measured in nature according to our knowledge. We provide a reference point for costs and benefits involved in inducible defenses of Daphnia pulex. The nature of costs owing to upward migration (increased metabolism, competition, and UV radiation) will have to be explored in future.

\section{Acknowledgements}

We thank Mark Ridgway and the 1999 crew of the Harkness Laboratories for Fisheries Research, Algonquin Park, for providing accommodation, field support, background data, field vehicles, and field equipment. We are also very grateful to Emily Smith, Christie Yee, and Kenyatta Esters for their assistance in the laboratory. This research was supported by funds from the Louisiana Education Quality Support Fund (LEQSF 1999-01-RD-A-13).

\section{References}

Boeing, W.J. 2002. Costs and benefits of Daphnia antipredator behavior and consequences on community stability. Ph.D. thesis, Louisiana State University, Baton Rouge, La.

Boersma, M. 1995. The allocation of resources to reproduction in Daphnia galeata: against the odds? Ecology, 76: 1251-1261.

Bottrell, H.H. 1975. The relationship between temperature and duration of egg development in some epiphytic Cladocera and Copepoda from the River Thames. Reading, with a discussion of temperature functions. Oecologia, 18: 63-68.
Carpenter, S.R., Kitchell, J.F., and Hodgson, J.R. 1985. Cascading trophic interactions and lake productivity. Bioscience, 35: 634639.

Davidson, N.L., Kelso, W.E., and Rutherford, D.A. 1998. Relationships between environmental variables and the abundance of cladocerans and copepods in the Atchafalaya River Basin. Hydrobiologia, 379: 175-181.

Dawidowicz, P. 1993. Diel vertical migration in Chaoborus flavicans: population patterns vs. individual track. Arch. Hydrobiol. 39: 19-28.

Dill, L.M., and Fraser, A.H.G. 1984. Risk of predation and the feeding behavior of juvenile coho salmon (Oncorhynchus kisutch). Behav. Ecol. Sociobiol. 16: 65-71.

Dodson, S.I. 1974. Zooplankton competition and predation: an experimental test of the size-efficiency hypothesis. Ecology, 55: 605-613.

Dodson, S.I. 1988. The ecological role of chemical stimuli for zooplankton: predator-avoidance behavior in Daphnia. Limnol. Oceanogr. 33: 1431-1439.

Ebert, D. 1993. The trade-off between offspring size and number in Daphnia magna: the influence of genetic, environmental and maternal effects. Arch. Hydrobiol. Suppl. 90: 453-473.

Grad, G., Williamson, C.E., and Karapelou, D.M. 2001. Zooplankton survival and reproduction responses to damaging UV radiation: a test of reciprocity and photoenzymatic repair. Limnol. Oceanogr. 46: 584-591.

Hanazato, T. 1990. A comparison between predation effects on zooplankton communities by Neomysis and Chaoborus. Hydrobiologia, 198: 33-40.

Haney, J.F., and Hall, D.J. 1973. Sugar coated Daphnia: a preservation technique for cladocerans. Limnol. Oceanogr. 18: 331333.

Havel, J.E. 1987. Predator-induced defenses: a review. In Predation: direct and indirect impacts on aquatic communities. Edited by W.C. Kerfoot and A. Sih. University Press of New England, Hanover, N.H. pp. 263-278.

Kajak, Z., and Rybak, J. 1979. The feeding of Chaoborus flavicans Meigen (Diptera, Chaoboridae) and its predation on lake zooplankton. Int. Rev. Gesamten Hydrobiol. 64: 361-378.

Kohler, S.L., and McPeek, M.A. 1989. Predation risk and the foraging behavior of competing stream insects. Ecology, 70: 18111825.

Krueger, D.A., and Dodson, S.I. 1981. Embryological induction and predation ecology in Daphnia pulex. Limnol. Oceanogr. 26: 219-223.

Lampert, W., McCauley, E., and Manly, B.F.J. 2003. Trade-offs in the vertical distribution of zooplankton: ideal free distribution with costs? Proc. R. Soc. Lond. B Biol. Sci. 270: 765-773.

Leech, D.M., and Williamson, C.E. 2000. Is tolerance to UV radiation in zooplankton related to body size, taxon, or lake transparency? Ecol. Appl. 10: 1530-1540.

Liljendahl-Nurminen, A., Horppila, J., Malinen, T., Eloranta, P., Vinni, M., Alajarvi, E., and Valtonen, S. 2003. The supremacy of invertebrate predators over fish - factors behind the unconventional seasonal dynamics of cladocerans in Lake Hiidenvesi. Arch. Hydrobiol. 158: 75-96.

Lüning, J. 1995. How do predator-induced changes affect prey vulnerability? Larvae of Chaoborus flavicans (Diptera: Chaoboridae) feeding on Daphnia pulex (Crustacea: Cladocera). Freshw. Biol. 34: 523-530.

Lurling, M., Roozen, F., Van Donk, E., and Goser, B. 2003. Response of Daphnia to substances released from crowded congeners and conspecifics. J. Plankton Res. 25: 967-978. 
Lynch, M. 1989. The life history consequences of resource depression in Daphnia pulex. Ecology, 70: 246-256.

McQueen, D.J., Johannes, M.R.S., Post, J.R., Stewart, T.J., and Lean, D.R.S. 1989. Bottom-up and top-down impacts on freshwater pelagic community structure. Ecol. Monogr. 59: 289-309.

McQueen, D.J., Ramcharan, C.W., Demers, E., Yan, N.D., Conforti, L.M., and Pérez-Fuentaja, A. 1999. Chaoborus behavioural responses to changes in fish density. Arch. Hydrobiol. 145: $165-179$.

Nesbitt, L.M., Riessen, H.P., and Ramcharan, C.W. 1996. Opposing predation pressures and induced vertical migration responses in Daphnia. Limnol. Oceanogr. 41: 1306-1311.

Parejko, K. 1991. Predation by chaoborids on typical and spined Daphnia pulex. Freshw. Biol. 25: 211-217.

Pastorok, R.A. 1981. Prey vulnerability and size selection by Chaoborus larvae. Ecology, 62: 1311-1324.

Ramcharan, C.W., Dodson, S.I., and Lee, J. 1992. Predation risk, prey behavior, and feeding rate in Daphnia pulex. Can. J. Fish. Aquat. Sci. 49: 159-165.

Ramcharan, C.W., Yan, N.D., McQueen, D.J., Pérez-Fuentetaja, A., Demers, E., and Rusak, J.A. 2001. Complex responses of Chaoborus to changes in fish populations. Arch. Hydrobiol. Spec. Issues Adv. Limnol. 56: 81-100.

Repka, S., Walls, M., and Ketola, M. 1995. Neck spine protects Daphnia pulex from predation by Chaoborus, but individuals with longer tail spine are at greater risk. J. Plankton Res. 17: 393-403.

Riessen, H.P. 1999. Predator-induced life-history shifts in Daphnia: a synthesis of studies using meta-analysis. Can. J. Fish. Aquat. Sci. 56: 2487-2494.

Riessen, H.P., and Sprules, G.W. 1990. Demographic costs of antipredator defenses in Daphnia pulex. Ecology, 71: 15361546.

Schwartz, S.S. 1991. Predator-induced alterations in Daphnia morphology. J. Plankton Res. 12: 1151-1161.

Sell, A.F. 1998. Adaptation to oxygen deficiency: contrasting patterns of hemoglobin synthesis in two coexisting Daphnia species. Comp. Biochem. Physiol. A Comp. Physiol. 120: 119-125.

Sih, A. 1982. Foraging strategies and the avoidance of predation by an aquatic insect, Notonecta hoffmanni. Ecology, 63: 15361546.

Spitze, K. 1992. Predator-mediated plasticity of prey life history and morphology: Chaoborus americanus predation on Daphnia pulex. Am. Nat. 148: 108-123.

Steiner, C.F. 2003. Variable dominance in pond communities: assessing spatiotemporal variation in competition and predation intensity. Ecology, 84: 982-990.
Stich, H.B., and Lampert, W. 1984. Growth and reproduction of migrating and non-migrating Daphnia species under simulated food and temperature conditions of diurnal vertical migration. Oecologia, 61: 192-196.

Tjossem, S.F. 1990. Effects of fish chemical cues on vertical migration behavior of Chaoborus. Limnol. Oceanogr. 35: 14561468.

Tollrian, R. 1993. Neckteeth formation in Daphnia pulex as an example of continuous phenotypic plasticity: morphological effects of Chaoborus kairomone concentration and their quantification. J. Plankton Res. 15: 1309-1318.

Tollrian, R., and Dodson, S.I. 1999. Inducible defenses in Cladocera: constraints, costs, and multipredator environments. In The ecology and evolution of inducible defenses. Edited by R. Tollrian and C.D. Harvell. Princeton University Press, Princeton, N.J. pp. 177-202.

Voss, S., and Mumm, H. 1999. Where to stay by day and night: size-specific and seasonal differences in horizontal and vertical distribution of Chaoborus flavicans larvae. Freshw. Biol. 42: 201-213.

Walls, M., Caswell, H., and Ketola, M. 1991. Demographic costs of Chaoborus-induced defences in Daphnia pulex: a sensitivity analysis. Oecologia, 87: 43-50.

Weber, A., and Declerck, S. 1997. Phenotypic plasticity of Daphnia life history traits in response to predator kairomones: genetic variability and evolutionary potential. Hydrobiologia, 360: 8999.

Weetman, D., and Atkinson, D. 2004. Evaluation of alternative hypotheses to explain temperature-induced life history shifts in Daphnia. J. Plankton Res. 26: 107-116.

Williamson, C.E. 1996. Effects of UV radiation on freshwater ecosystems. Int. J. Environ. Stud. 51: 245-256.

Williamson, C.E., and Stoeckel, M.E. 1990. Estimating predation risk in zooplankton communities: the importance of vertical overlap. Hydrobiologia, 198: 125-131.

Winder, M., Boersma, M., and Spaak, P. 2003. On the cost of vertical migration: are feeding conditions really worse at greater depths? Freshw. Biol. 48: 383-393.

Young, J.D. 2002. The influence of morphological and behavioural differences in the planktonic predator Chaoborus on Daphnia population growth rate. M.A. thesis, State University of New York College at Buffalo, Buffalo, N.Y. 